
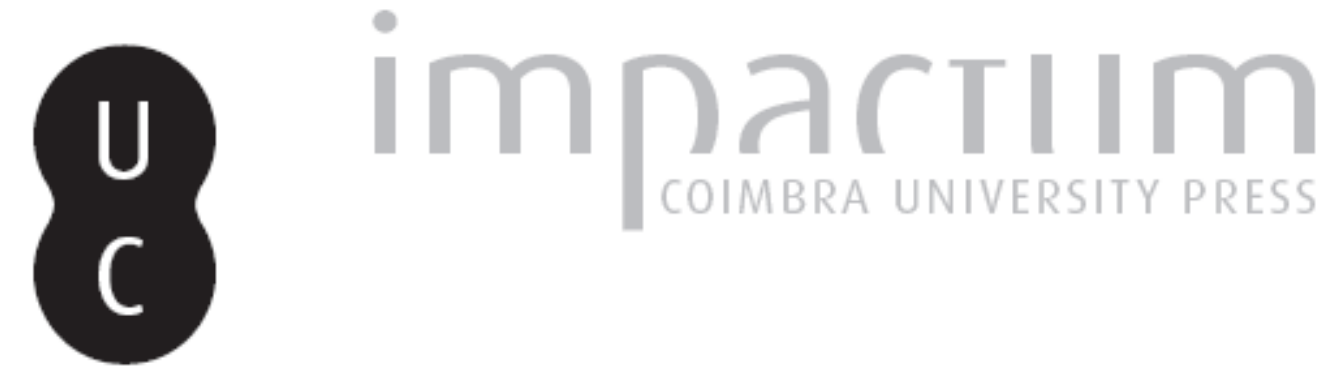

\title{
[Recensão a] Nur El-din, Abd El-Halim - The Ancient Egyptian Language, Alexaridria: Bibliotheca Alexandrina
}
Autor(es):
Araújo, Luís Manuel
Publicado por: Centro de História da Universidade de Lisboa
URL persistente:
URI:http://hdl.handle.net/10316.2/23796
DOI:
DOI:http://dx.doi.org/10.14195/0871-9527_19_19
Accessed : $\quad$ 26-Apr-2023 09:47:56

A navegação consulta e descarregamento dos títulos inseridos nas Bibliotecas Digitais UC Digitalis, UC Pombalina e UC Impactum, pressupõem a aceitação plena e sem reservas dos Termos e Condições de Uso destas Bibliotecas Digitais, disponíveis em https://digitalis.uc.pt/pt-pt/termos.

Conforme exposto nos referidos Termos e Condições de Uso, o descarregamento de títulos de acesso restrito requer uma licença válida de autorização devendo o utilizador aceder ao(s) documento(s) a partir de um endereço de IP da instituição detentora da supramencionada licença.

Ao utilizador é apenas permitido o descarregamento para uso pessoal, pelo que o emprego do(s) título(s) descarregado(s) para outro fim, designadamente comercial, carece de autorização do respetivo autor ou editor da obra.

Na medida em que todas as obras da UC Digitalis se encontram protegidas pelo Código do Direito de Autor e Direitos Conexos e demais legislação aplicável, toda a cópia, parcial ou total, deste documento, nos casos em que é legalmente admitida, deverá conter ou fazer-se acompanhar por este aviso.

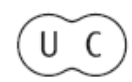



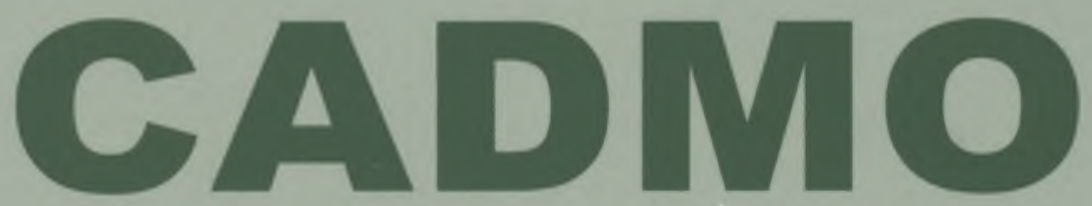

Revista de História Antiga

\author{
Centro de História \\ da Universidade de Lisboa
}

19

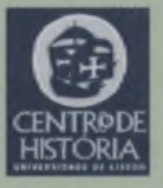

430 =

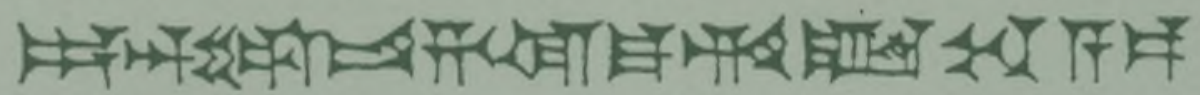

MHNIN AEI $\Delta$ E $\Theta E A ~ \Pi H \Lambda H I A \triangle E \Omega$ 
ABD EL-HALIM NUR EL-DIN, The Ancient Egyptian Language, Alexandria: Bibliotheca Alexandrina, 2007, 288 pp., ISBN 978-977-6163-60-7.

O egiptólogo Abd el-Halim Nur el-Din, professor de Língua Egípcia Antiga na Universidade de Alexandria, achou por bem traduzir para inglês a sua gramática original escrita em árabe para uso dos seus alunos de Egiptologia. E ainda bem que o fez, porque assim o volume fica agora ao alcance de um muito maior leque de leitores em todo o mundo. E quem já dispõe da clássica gramática de Sir Alan Gardiner (Egyptian Grammar, 1957), para além das proveitosas edições de James P. Allen (Middle Egyptian, 2001), Mark Collier e Bill Manley (How to Read Egyptian Hieroglyphs, 1998), para apenas mencionar algumas edições em língua inglesa, pode desta feita juntar este novo contributo de um dos mais conceituados egiptólogos egípcios da actualidade.

O volume abre com os agradecimentos (pp. 9-10) e com uma "Introduction", a qual inclui sucintos dados preliminares sobre "The Birth of Writing in Ancient Egypt» (pp. 11-13), com breves explicações acerca das bases do sistema em "Hieroglyphic Writing" (pp. 13-14), evocando-se, a seguir, "The Rosetta Stone and the Ancient Egyptian Language" (pp. 14-15), e esclarecendo-se as várias "Scripts of the Ancient Egyptian Language» (15-17), com "The Transition from one Script to Another and Why" (p. 18), as "Linguistic Phases of the Ancient Egyptian Language" (pp. 19-20) e "Arrangement and Direction of Writing" (p. 20).

Depois desta oportuna introdução, ficará o leitor preparado para entrar no capítulo 1, com um novo texto de timbre introdutório: «Introduction to the Ancient Egyptian Language» (pp. 21-28). Aqui são enumerados os signos utilizados e descritos os princípios gerais da escrita hieroglífica, o significado dos signos e a sua posição na escrita tendo em conta questões de ordem estético-gráfica, os complementos fonéticos, os signos supérfluos e defectivos. O capítulo termina com um pequeno grupo de exercícios propostos aos alunos, método que é seguido no final dos restantes capítulos da obra, propiciando uma sólida apreensão da matéria dada.

O capítulo 2 apresenta "Verbs in the Ancient Egyptian Language» (pp. 29-36), começando com o basilar «Egyptian Verb Structure and Class", com o esperado destaque para a forma sdm.f, seguindo-se "Tense and Mood in Egyptian Verbs", "Verb Type and Function" e a rematar "Active and Passive Voice". 
Com o capítulo 3 são facultadas as listas dos imprescindíveis "Personal Pronouns», desde os "Suffix Pronouns» (pp. 37-39), os «Dependent Pronouns" (pp. 40-42), os «Independent Pronouns» (pp. 42-43) e os "Compound Pronouns" (pp. 43-44).

"Nouns in the Ancient Egyptian Language" é o assunto do capítulo 4, o qual inclui os «Nouns» (pp. 45-47), «Demonstratives (p. 48), "Possessive Adjectives" usados com frequência em lugar das construções de tipo genitivo (p. 49), complementados com "Sentences Expressing Possession» (pp. 49-50), "Genitives» (pp. 50-52), «Apposition» (p. 52), "Coordination" e "Disjunction" (p. 53).

O capítulo 5 trata dos "Adjectives and Comparison" (pp. 55-60), os "Nisba Adjectives", "Comparative and Superlative", e a enfatização adjectival apresentada aqui como «Exclamatory Force».

Com o capítulo 6 são facultados os "Numbers and Fractions" (pp. 61-64), merecendo nota de relevo as "Measures", elaboradas com o curioso recurso às várias partes do olho mágico e apotropaico do deus Hórus (udjat).

As formas negativas são o tema do capítulo 7 (pp. 65- 68), com a "Negation", as "Negative Particles", "Negative Construction» e os «Negative Verbs».

O capítulo 8 trata das "Particles in the Ancient Egyptian Language» (pp. 69-75), e engloba a "Interrogation and Interrogative Particles", "Enclitic and Non-Enclitic Particles", "Conditional Particles", as «Interjections" e as "Prepositions".

O denso tema das frases verbais é explicado no capítulo 9, com "Sentences in the Ancient Egyptian Language» (pp. 79-98), incidindo nas "Verbal Sentences», "Existencial Sentences», "The Auxiliary Verb ḩ", "Conditional Clause» e "Non-Verbal Clauses», aqui se incluindo as frases não verbais com predicado nominal ou pronominal, com predicado adjectival e com predicado preposicional ou adverbial.

O capítulo 10 apresenta um aspecto característico da escrita hieroglífica, a "Anticipation in the Ancient Egyptian Language" (pp. 99-101), com a "Honorary Transposition» e "Anticipatory Emphasis".

As comuns "Relative Clauses" são explicitadas no capítulo 11 (pp. 103-106), o qual inclui "Relative Clause», "Virtual Relative Clauses» $\mathrm{e}$ "Negation of Relative Clause».

O capítulo 12 trata de duas formas derivadas de formas verbais, o "Infinitive and Stative (Old Perfective)" (pp. 107-115).

Finalmente o capítulo 13 trata de "Active Participle, Passive Participle, Relative Form and Imperative» (pp. 117-132). 
Segue-se um encorpado núcleo de apêndices (pp. 133-205), que incluem "English terms and their equivalents in French and German" (pp. 133-138), «Position of Dots and Strokes and their Phonetic Implication» (pp. 139-147), "Introduction to Reading Ancient Egyptian Names» (pp. 149-168), "Introduction to Reading Deities Names» (pp. 169-184), "Names of Egypt known from ancient times» (pp. 185-186) e "Royal Epithets, Royal Crowns, Vocabularies and Usual Formulae used in Scenes and Texts from Ancient Egypt» (pp. 187-205).

O volume, de paginação agradável, vai rematar com a lista de signos hieroglíficos, seguindo a proposta de organização idealizada por Sir Alan Gardiner há já muitos decénios (pp. 209-275), um índice de signos com a respectiva numeração gardineriana identificadora ( $p p$. 279-284), e uma útil bibliografia (pp. 285-287).

Os leitores interessados na aprendizagem da escrita hieroglífica, a começar naturalmente pelos alunos universitários que nos seus cursos dispõem de uma cadeira (unidade curricular opcional) dedicada a este tema, poderão, com sumo proveito, utilizar este volume do professor Abd el-Halim Nur el-Din, que em boa hora produziu esta gramática cuja vocação pedagógica é reforçada pelo facto de no final de cada capítulo serem propostos exercícios sobre a matéria apresentada.

\section{Luís Manuel de Araújo}

DAVID SOLER e JAVIER VILLALBA (dir.), História da Humanidade. O Egipto e as Antigas Civilizações, Lisboa: Círculo de Leitores, 2007, 412 pp. (profusamente ilustrado), ISBN 078-972-42-4118-0.

Com a habitual qualidade gráfica das edições do Círculo de Leitores, que conta entre os seus títulos diversas obras de temática histórica, dispõem agora os leitores de língua portuguesa de mais um volume onde o Egipto é o tema dominante. Ele não é de facto o único, dado que este bem ilustrado álbum contempla outras civilizações, mas é a atraente civilização egípcia que acaba por assumir destaque, desde logo enfatizada no próprio título, se bem que seja o quarto tema do volume, depois da Mesopotâmia e de outras civilizações e culturas. Já o original espanhol, editado em Barcelona, apresentava como título Historia de la Humanidad: Egipto y las civilizaciones antiguas. 